\title{
ANÁLISE DE REDES SOCIAIS A PARTIR DO USO DA INFORMAÇÃO ESPACIAL
}

\author{
An analysis of social networks from spatial information \\ LUCIENE STAMATO DELAZARI \\ MARIA CECILIA BONATO BRANDALIZE \\ Universidade Federal do Paraná \\ Departamento de Geomática \\ Programa de Pós-Graduação em Ciências Geodésicas \\ CEP: 81531-990 - Centro Politécnico - Curitiba - Paraná - Brasil \\ luciene@ufpr.br; maria.brandalize@ufpr.br
}

\begin{abstract}
RESUMO
Este artigo apresenta a pesquisa desenvolvida sobre redes de proteção social, com enfoque na metodologia empregada para gerar as representações cartográficas dos seus diferentes aspectos. A pesquisa foi conduzida em Curitiba, tendo por base os direitos sociais: Terra e Habitação, Saúde, Educação, Trabalho, Segurança Alimentar e Assistência Social; e permitiu uma primeira aproximação das análises, numa abordagem inédita para avaliar as interações entre os diferentes atores levantados para cada um dos direitos mencionados. As redes sociais normalmente se desenvolvem por meio da Internet, e por isso têm caráter dinâmico. Deste modo, as representações cartográficas foram desenvolvidas considerando o espaço geográfico e também o ciberespaço. A realização destas representações compreendeu as etapas de coleta de dados (por meio de sítios da Internet), classificação e representação, sendo que esta última envolveu a adaptação das formas convencionais de representação de dados espaciais aos dados das redes, especificamente no que se refere ao ciberespaço.
\end{abstract}

Palavras-chave: Redes Sociais; Projeto Cartográfico; Ciberespaço.

\begin{abstract}
This paper presents a research project that has been developed at the Federal University of Parana (Brazil) and its main purpose is to analyze, from the point of view of the cartographic representations, the different aspects of social networks representation which are specifically focused at the protection of the individuals'
\end{abstract}

Bol. Ciênc. Geod., sec. Artigos, Curitiba, v. 18, nº 2, p.185-202, abr-jun, 2012. 
social rights. The research work was held in Curitiba (Capital City of Parana State Brazil), taking as basis the cartographic representation of the following social rights' networks: Land and Housing, Health, Education, Labor, Food Safety and Social Assistance. The cartographic representation of these networks has led to new representation approaches in this area and also to a more effective analysis of the interactions among the different actors of the networks mentioned. Social networks are usually established on the Internet and have a dynamic character. Thus, the cartographic representations were designed considering both the geographic space and cyberspace. The development of these cartographic representations followed the steps of data collection, classification and representation. In the last step the conventional forms of representation have been adapted to network data, specifically concerning cyberspace.

Keywords: Social Networks; Cartographic Design; Cyberspace.

\section{INTRODUÇÃo}

As redes sociais são formadas por entidades que compartilham funções, propósitos ou perspectivas. As entidades, também chamadas de atores, são representadas pelos nós, que se interligam, dependendo da relação existente entre eles. Os atores podem ser indivíduos, bem como organizações corporativas ou coletivas que se interligam por laços sociais (CONTRACTOR, WASSERMAN e FAUST, 2006; WASSERMAN e FAUST, 1999).

A representação espacial apresentada neste artigo trata das redes sociais formadas por atores localizados no município de Curitiba - PR e relacionados a um dos seguintes direitos da população: Saúde, Habitação, Educação, Assistência Social, Segurança Alimentar e Trabalho. Esta rede recebe o nome de rede de proteção social.

Entre as associações que congregam organizações não governamentais e movimentos sociais, as redes sociais são atualmente compreendidas como “comunidades, virtual ou presencialmente constituídas" que operam em escala local, regional, nacional e internacional, objetivando a troca de informações, a "articulação institucional e política e a implementação de projetos comuns" (RITS, 2006).

Assim, pode-se concluir que as redes sociais são estruturas dinâmicas, o que por consequencia faz com que as relações entre os atores sejam resultado das localizações geográficas e dos relacionamentos espaciais entre os atores e com outros fenômenos espaciais.

Segundo Kauchakje et al (2006), a gestão territorial atual apresenta uma visão menos hierárquica da gestão, com o planejamento e as decisões realizadas não só pelo poder executivo, mas em forma de cooperação por meio das redes. Nestas estruturas, os pontos não estão relacionados por subordinação, mas por afinidades (sociais, culturais e econômicas). Além disso, parte destas redes é criada ou potencializada pelas tecnologias da informação e comunicação (TICs) e são 
chamadas de redes sócio-técnicas, visto que os agentes sociais estão organizados e mediados por instrumentos tecnológicos de modo que os laços entre os diferentes agentes sejam efetivos. Deste modo, segundo os autores, é fundamental compreender as relações sociais, os instrumentos tecnológicos e a base territorial como elementos interdependentes na constituição de tais redes.

Para Dodge e Kitchin (2001), o espaço, no pensamento geográfico, pode ser entendido como sendo tanto absoluto (no sentido Aristotélico: estático, hierárquico e concreto; no sentido Newtoniano: onde objetos são localizados e eventos ocorrem) como relativo (no sentido Leibniziano: definido em termos de relacionamentos; no sentido Kantiano: conceituado como uma forma imposta ao mundo pelo homem). Os mesmos autores, ao evocar Lefebvre (1991), concordam que o espaço está sendo continuamente produzido através das relações sócio-espaciais sendo que o seu processo de espacialização se dá em três níveis complementares, quais sejam: as práticas espaciais (onde); as representações espaciais (mapas); e os espaços de representação (ideologias). Portanto, Dodge e Kitchin (2001) conceitualizam o espaço geográfico como relacional, tanto no sentido geométrico como no sentido social. Estes ainda concordam que a análise geográfica tradicional dos espaços produzidos socialmente através das Tecnologias de Informação e Comunicação (TICs), mais especificamente, os produzidos ciberneticamente através da Rede Mundial de Computadores (WWW) e da Internet, constitui um desafio, pois este tipo de representação rompe com as premissas cartográficas de que o espaço é contínuo e ordenado.

A complexidade em se tentar representar geograficamente as redes sociais que se estabelecem através das TICs e do espaço cibernético (ciberespaço), reside no fato de que estes não possuem limites físicos estabelecidos, atributos espaciais necessários à sua materialização e espacialização. No entanto, os cartógrafos tendem a estender os métodos empregados na produção de mapas e visualização do espaço geográfico convencional, à produção de mapas e às visualizações dos espaços virtuais e de suas inter-relações. De qualquer forma, esta solução, embora nem sempre satisfatória, constitui ainda a única alternativa disponível, pois, somente uma mudança radical na forma de pensar o espaço poderia levar a uma nova concepção do seu mapeamento.

Assim, apesar da importância da visualização das redes sociais através da sua variável espacial geográfica, é comum, ainda hoje, que as articulações entre os agentes sociais que compõem estas redes sejam apresentadas e analisadas com base em tabelas, fluxos e grafos, este último, representando a forma mais comum de visualização espacial não geográfica das ligações entre tais agentes (FREY, 1996; MARQUES, 2000, 2003). Entretanto, os grafos não consideram a localização geográfica dos atores e suas ligações, de modo que não é possível entender e analisar a estrutura espacial de tais redes.

Deste modo, o presente trabalho propõe apresentar uma estratégia metodológica para representar espacialmente as redes sociais, tendo por base, em primeiro lugar, os dados coletados sobre os diferentes direitos sociais (temas) 
apresentados a partir da Rede Mundial de Computadores (WWW); e, em segundo lugar, o município de Curitiba como "nó” geográfico principal ou central (ground zero da rede). Tais dados foram classificados e, a partir da sua representação geográfica, foram realizadas análises que permitiram inferir sobre a extensão e a efetividade das políticas públicas municipais, a nível local (intramunicipal), regional (intermunicipal) e global.

\section{REPRESENTAÇÃO DE REDES SOCIAIS}

\section{Abordagem convencional}

A importância da representação cartográfica para os cientistas sociais pode ser entendida quando se faz a comparação entre os grafos, matrizes e mapas. As análises decorrentes dependem também dos softwares utilizados e devem considerar as capacidades para gerar e manipular estas representações. Os dois softwares mais populares utilizados para representação das redes são o UCINET e o Pajek. Estes softwares foram projetados e implementados com base nas teorias desenvolvidas pelos próprios cientistas sociais. Neles as redes são representadas por grafos e matrizes.

O grafo consiste de pontos (nós) para representar os atores e arcos para representar as relações ou ligações. Estes grafos são denominados sociogramas. A Figura 1 apresenta um dos grafos gerados com o programa UCINET para a representação da rede de segurança alimentar em Curitiba e sua respectiva tabela de atores (observa-se que na legenda da figura não estão listados todos os pontos por questões de espaço).

Figura 1 - Representação da Rede Social de Segurança Alimentar em Curitiba.

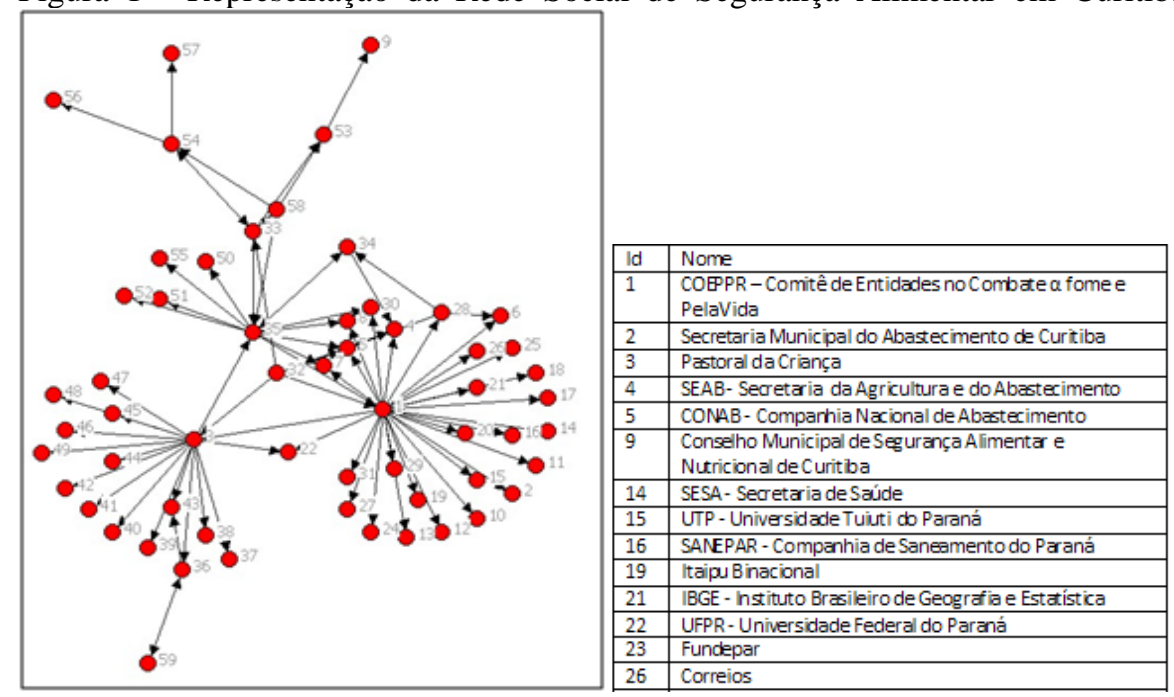

Bol. Ciênc. Geod., sec. Artigos, Curitiba, v. 18, nº 2, p.185-202, abr-jun, 2012. 
Tabela 1 - Exemplo de Matriz de Relacionamento

\begin{tabular}{ccccccc}
\hline ID & $\mathbf{1}$ & $\mathbf{2}$ & $\mathbf{3}$ & $\mathbf{4}$ & $\mathbf{5}$ & $\ldots$ \\
\hline $\mathbf{1}$ & 0 & 1 & 1 & 1 & 1 & \\
\hline $\mathbf{2}$ & 1 & 0 & 0 & 0 & 0 & \\
\hline $\mathbf{3}$ & 1 & 0 & 0 & 0 & 0 & \\
\hline $\mathbf{4}$ & 1 & 0 & 0 & 0 & 1 & \\
\hline $\mathbf{5}$ & 1 & 0 & 0 & 1 & 0 & \\
\hline $\boldsymbol{\ldots}$ & & & & & & \\
\hline
\end{tabular}

No caso da representação dos relacionamentos em uma tabela (Tabela 1), as relações são explicitadas pelos valores correspondentes em cada posição. Se o ator tem relação com outro, atribui-se, por exemplo, o valor um (1), caso contrário, atribui-se o valor zero (0).

O software UCINET contém um conjunto de funções para o cálculo de proximidade entre os atores e identificação de subgrupos. As medidas baseiam-se na condição de que a posição de cada ator é influenciada pelo seu relacionamento, no caso a ligação, aos outros atores. Esta condição é uma consequência da teoria dos grafos. Assim, é possível alterar a posição de um ator sem mudar a estrutura da rede, desde que as ligações permaneçam inalteradas.

A maior diferença entre dados convencionais e de redes é que estes focam atores e suas inter-relações, enquanto que os dados convencionais focam atores e atributos. As análises de redes enfatizam, portanto, as relações entre atores, o que significa que estes normalmente não são amostrados independentemente, como no caso de outros tipos de dados.

As representações sob a forma de grafos apresentam dois problemas:

(1) As localizações espaciais dos nós da rede não são representadas e;

(2) As soluções gráficas não são definidas de maneira a representar os atributos dos componentes dos grafos.

Estes problemas necessitam de solução, pois:

a) A representação das localizações espaciais é necessária para as análises de conhecimento sobre as relações de proximidade e vizinhança, enquanto a representação dos atributos (características) dos componentes dos grafos é necessária para a análise de agrupamentos, dispersões, tendências, entre outras;

b) As localizações espaciais permitem conhecer fluxos em termos de regiões de influência culturais, políticas e econômicas na dinâmica das articulações das redes sociais; e,

c) A espacialização da rede e dos tipos de enlaces (ligações entre os nós) pode indicar uma espécie de divisão (de local para global) e, até mesmo, uma maior capacidade de coordenar e concentrar recursos e meios (financeiros e humanos, em especial) para a realização ou apoio a ações 
sociais.

Existem proposições e debates teóricos sobre a metodologia de análise de redes sociais locais, regionais e nacionais utilizando aportes teóricos e softwares próprios. Segundo Wasserman et al. (2005), o interesse pelas análises das redes sociais tem crescido significativamente nos últimos anos. Este crescimento tem sua justificativa no aumento de sofisticação das técnicas e ferramentas disponíveis aos usuários. Os mesmos autores apresentam os modelos e métodos quantitativos mais importantes para análise de redes sociais surgidos após 1990. Apesar deste desenvolvimento e dos métodos e técnicas apresentadas por Wasserman et al (2005), não foram apresentados estudos que busquem diferentes meios de representação das redes de modo a aumentar o poder de análise sobre elas.

\subsection{Redes Sociais e suas Representações no Ciberespaço}

Autores como Dodge e Kitchin (2001), Dodge (2002 e 2003), Prada (2008) e Pontin (2008) afirmam que as Tecnologias de Informação e Comunicação (TICs) são tecnologias transformadoras que modificam a sociedade de diferentes formas. Isto ocorre, principalmente, porque facilitam o processo de reestruturação da sociedade, alterando radicalmente a vida social, cultural, política, institucional e econômica dos indivíduos. Assim, as TICs rompem uma série de processos e de conceitos fundamentais que são a base das epistemologias e da sociedade moderna.

O ciberespaço e a infraestrutura (TICs) que o suporta, referem-se ao espaço digital e navegável de uma rede de computadores, pelos quais indivíduos interagem e trocam informações (DODGE e KITCHIN, 2001). A importância do ciberespaço e das TICs para este projeto reside no crescimento exponencial, verificado na última década, do número de usuários da Rede Mundial de Computadores (WWW) e nas consequentes possibilidades que estes usuários têm de acessar/trocar informações com poder de transformar suas vidas em muitos sentidos. Estas tecnologias, segundo Dodge e Kitchin (2001), facilitam o processo de reestruturação da sociedade, alterando-a social, cultural, política, institucional e economicamente. Uma vez que os sistemas modernos do pensamento são fundamentalmente dualísticos, o ciberespaço, neste contexto, é frequentemente questionado em relação às suas características espaciais/não-espaciais; pública/privada; natural/tecnológica; real/virtual; fixa/fluida; de localização/deslocalização; entre outras. Como explicitado anteriormente, a produção do espaço e o seu processo de espacialização compreendem três níveis complementares: as práticas espaciais, as representações do espaço (por exemplo, através de mapas) e os espaços de representação (imbuídos de conteúdo ideológico e que, neste trabalho, compreendem os atores que compõem as redes sociais de garantia dos direitos sociais já mencionadas). Estes níveis interagem e produzem uma espacialidade complexa de difícil visualização e interpretação. Por esta razão, é necessário construir as geometrias espaciais do ciberespaço, identificando-o física e espaço-temporalmente. Assim, o ciberespaço e as relações que nele se configuram podem ser mapeados relativamente ao espaço geográfico e representados por meio de técnicas cartográficas modernas. 
O mapeamento desta infraestrutura e do fluxo de informação (redes) compreende diferentes tipos de representação em função do dado ou informação que se apresenta. Entre os tipos de representação mais comuns, encontram-se: mapas estáticos, mapas animados, mapas interativos e mapas dinâmicos (DODGE e KITCHIN, 2001).

A visualização do dado ou da informação, nestes casos, possui um foco particular no desenvolvimento e no aperfeiçoamento das interfaces entre o usuário e os espaços informacionais produzidos pelas redes sociais.

Embora, para alguns autores, a localização geográfica da infraestrutura do ciberespaço não seja importante, a maioria das espacializações produzidas quando da representação de redes sociais virtuais, revela, através de um sistema de localização relativa como nos grafos, outros tipos de relação, como, por exemplo, a conectividade, o sentido e a intensidade de fluxo entre os atores e que, de outra forma, não seriam percebidos, por exemplo, nas representações matriciais ou me forma de tabela. Como exemplo, na Figura 2 (a e b) apresentam-se, respectivamente, o aspecto geral e um detalhamento do grafo dinâmico gerado online relativamente à rede de segurança alimentar em Curitiba. No detalhamento é possível perceber que fazem parte da referida rede os seguintes atores: Portal do Ministério da Agricultura, Banco Nacional do Desenvolvimento (BNDES), Brazil Trade Net, Ministério do Meio Ambiente (MMA), entre outros.

Figura 2a - Representação Online da Rede Social de Segurança Alimentar em Curitiba: Aspecto Geral do Grafo.

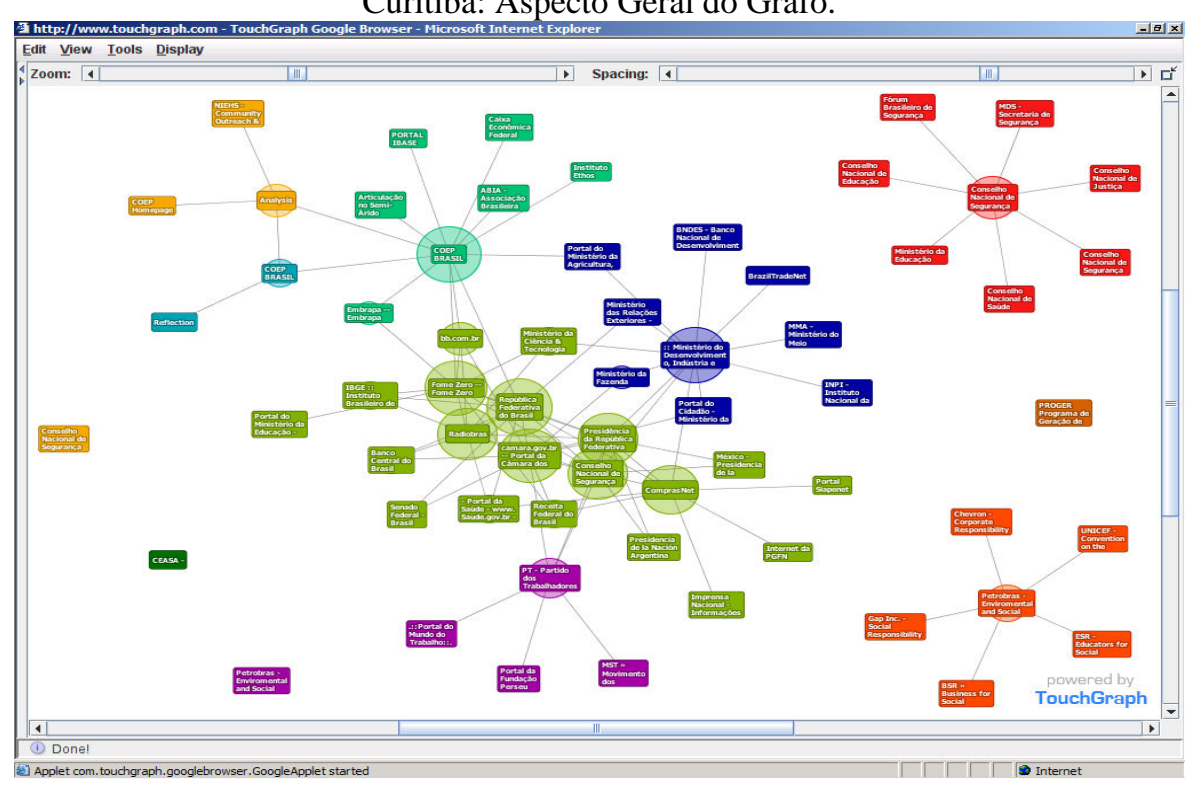


Figura 2b - Representação Online da Rede Social de Segurança Alimentar em Curitiba: Detalhamento do Grafo.

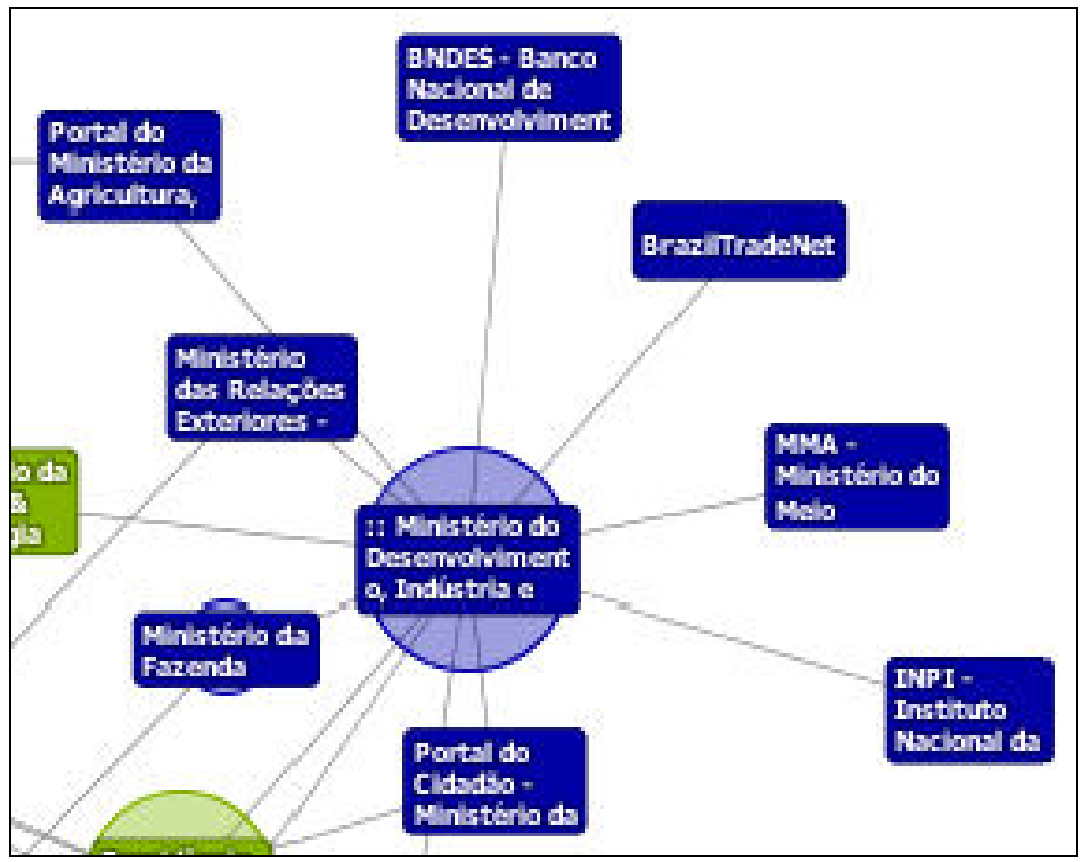

Na figura 3, parte da tabela de atores que corresponde a este grafo é apresentada. Esta representação foi realizada automaticamente através do uso de um aplicativo que investiga as múltiplas relações entre os sítios que compõem uma determinada rede em função de palavras chaves (busca semântica).

Uma vez que as redes sociais se formam e se desenvolvem no ciberespaço com o suporte das TICs, há um variado número de aplicativos que são desenvolvidos e disponibilizados a fim de controlar e mapear a informação que circula por este espaço virtual.

No caso específico das redes sociais de garantia dos direitos sociais as relações entre os diferentes atores da rede, para cada direito social mencionado, ocorrem através do que é informado como conteúdo do sítio (principalmente sob a forma de texto e de hyperlinks). Assim, a visão de que o geocódigo, ou seja, de que a chave utilizada nos Sistemas de Informações Geográficas para relacionar primitivas gráficas a seus atributos não existe ou é impossível de obter no ciberespaço, não é de todo verdade. O que ocorre é que o ciberespaço não é regido pelos princípios ordinários de espaço e tempo, porém, não deixa de ser uma geografia mental comum (GIBSON, 1984). 
Figura 3 - Representação Online da Rede Social de Segurança Alimentar em Curitiba: Parte da Tabela de Atores que Corresponde ao Grafo - Ênfase no

Detalhamento.

\begin{tabular}{|c|c|c|c|}
\hline \\
\hline Info & Help & & \\
\hline \multicolumn{4}{|c|}{$\Delta \rightarrow$} \\
\hline \multicolumn{4}{|c|}{ Filter } \\
\hline \multirow{2}{*}{ Show Hidden } & & \multicolumn{2}{|l|}{ Name } \\
\hline & ] & & \\
\hline & Name & URL & Sim\#. \\
\hline$\theta$ & Portal da Fundação Perseu Abramo - Uma nova cultura políti & fpabramo.org.br & 1 \\
\hline$\oplus$ & $\because$ Ministério do Desenvolvimento, Indústria e Comércio Exteri & desenvolvimento.gov.br & 12 \\
\hline$\theta$ & Portal do Ministério da Agricultura, Pecuária e Abastecimento & agricultura.gov.br & 2 \\
\hline$\theta$ & Portal do Cidadäo - Ministério da Justiça do Brasil & mj.gov.br & 2 \\
\hline$\oplus$ & Ministério das Relaçōes Exteriores - INíCIO & mre.gov.br & 2 \\
\hline$\theta$ & Ministério da Fazenda & fazenda.gov.br & 2 \\
\hline$\theta$ & MMA - Ministério do Meio Ambiente & mma.gov.br & 1 \\
\hline$\theta$ & BrazilTradeNet & braziltradenet.gov.br & 1 \\
\hline$\theta$ & INPI - Instituto Nacional da Propriedade Industrial & inpi.gov.br & 1 \\
\hline$\theta$ & BNDES - Banco Nacional de Desenvolvimento Econômico e & bndes.gov.br & 1 \\
\hline$\theta$ & Analysis & coepbrasil.org.bridownloads/04-57C-e-JSaxby.pdf & 4 \\
\hline$\oplus$ & NIEHS - Community Outreach \& Education Program & eohsi.rutgers.edu/niehs/coep.shtml & 1 \\
\hline$\theta$ & COEP Homepage & coepalumninet & 1 \\
\hline
\end{tabular}

Assim, o ciberespaço compreende espaços abstratos libertos da geometria euclidiana e do mapeamento cartesiano, constituindo um espaço onde os axiomas da topologia e da geometria, tão compelidamente observados como sendo parte integral da natureza, podem ser violados ou reinventados como a maioria das leis da física (BENEDICKT, 1991). Além disso, constituem um espaço onde o tempo não existe (não é seqüencial) e onde só existem dois estados: presença e ausência, agora ou nunca (STALDER, 1998). Vale ressaltar ainda que o acesso ao ciberespaço é individual e autônomo e, embora grande parte da população mundial não faça parte das redes que nele se estabelecem, não se pode negar sua influência nos padrões econômicos mundiais e na reestruturação dos espaços urbano-regionais. Assim, um claro entendimento deste ambiente virtual complexo através dos mapas, reduz o tempo de busca por soluções e revela relacionamentos espaciais que, de outra forma, não seria possível.

\section{METODOLOGIA}

O desenvolvimento desta pesquisa foi realizado por meio da pesquisa empírica, com as seguintes técnicas e instrumentos:

a) Coleta de dados: entrevista estruturada, análise de documentos e pesquisa em sítios da Internet; 
b) Proposições: projeto e apresentação de soluções gráficas (espaciais e não espaciais) para a representação das redes sociais (offline e online), utilizando softwares específicos para a geração de mapas e/ou localização de elementos geográficos (UCINET, TOUCHGRAPH, ARCGIS e GOOGLE EARTH/MAPS);

c) Análise: sistematização dos resultados e verificação da eficiência das representações propostas.

\subsection{Coleta de Dados e Representação Gráfica (Espacial e Não-Espacial) da} Rede de Proteção Social em Curitiba

Para a identificação da rede de agentes sociais foram adaptados os procedimentos metodológicos desenvolvidos por Kauchakje et al. (2006), que centra a coleta de dados em sítios da Internet. Considera-se que na web os agentes sociais articulam-se em redes temáticas, por identidade e através da realização de projetos referenciados por links. Estas inter-relações têm as seguintes características (KAUCHAKJE, 2008):

a) Parceria Temática: constituída por atores que expressam certa constância de propósitos declarados, tanto em termos de missão/tema das ações quanto de objetivos. Estes atores não precisam, necessariamente, compartilhar valores, ideários, concepções políticas, causas ou projetos sociais, mas têm suas atividades direcionadas para a mesma temática ou política;

b) Parceria Identitária: os atores atuam no mesmo campo temático com compartilhamento de valores, ideários, concepções políticas, causas sociais e ou projetos societários. Esta parceria sugere laços fortes de longa duração e permanência de articulação;

c) Parceria em Projeto: expressa a cooperação mútua em programas, projetos, ações e iniciativas conjuntas, ações coordenadas entre atores concretamente desenvolvidas nas cidades pesquisadas. Os parceiros em projeto, ao menos durante o seu desenvolvimento, costumam ser também temáticos, mas não necessariamente ideológicos. No caso dos patrocinadores/apoiadores de projetos, esta parceria pode ser temporalmente limitada à duração do projeto ou das ações desenvolvidas. Esta parceria sugere ainda a existência de laços entre os agentes sociais que podem ser fortes ou fracos, permanentes ou temporários, e que se estabelecem, no mínimo, durante o desenvolvimento da ação/projeto enunciado;

d) Parcerias de Apoio e Colaboração: são relações entre organizações sociais nas quais as inter-relações estão baseadas na disponibilização de recursos financeiros ou de outra espécie;

e) Hyperlinks de Referência: apresentam relações de referência sobre o campo de interesse, valores e universo temático das organizações entre si.

Bol. Ciênc. Geod., sec. Artigos, Curitiba, v. 18, nº 2, p.185-202, abr-jun, 2012. 
A representação cartográfica destas ligações foi realizada considerando o nível de medida nominal, com a utilização da variável visual tom de cor, como ilustra a figura 4.

Figura 4 - Classificação dos Enlaces.

Enlaces

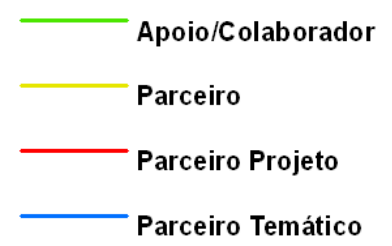

Para o caso dos atores, estes podem ser governamentais, não governamentais, empresas, conselhos e outros. No caso dos atores não governamentais, segue a classificação adotada:

a) ONGs Ativistas ou Movimentalistas: associações de educação e assessoria popular que objetivam a democratização social e política, bem como, a defesa e consolidação de direitos e cidadania. No geral, têm relações com movimentos sociais, mas também podem estar articuladas a setores de partidos políticos, igrejas e empresas cujos propósitos sócio-políticos são afins.

b) ONGs Filantrópicas: associações que têm a missão de atuar no campo da ajuda e da proteção aos considerados necessitados e carentes. As pessoas que compõem estas ONGs podem ter motivação humanitária ou comungá-la com princípios religiosos numa relação estreita com igrejas; neste caso, pode-se denominá-las de ONGs confessionais. As filantrópicas laicas ou confessionais são no geral denominadas de ONGS prestadoras de serviços.

c) ONGs Empresariais: associações sem fins lucrativos que são vinculadas às ações de responsabilidade social de determinadas empresas, as quais em contrapartida podem obter benefícios fiscais. No geral, atuam por projetos de cunho humanitário e de proteção sócio-ambiental.

De acordo com as categorias de atores citadas, a proposta metodológica possui dois momentos entrelaçados e distintos: os procedimentos de coleta e representação dos dados e informações; e os procedimentos de análise, subdivididos nos seguintes itens:

a) Seleção da temática no âmbito dos direitos sociais com o recorte territorial;

b) Busca na Internet de organizações sociais referentes à temática; 
c) Definição dos atores significativos;

d) Reconhecimento, em cada sítio, dos atores de ações e projetos comuns, articulações temáticas e identitárias e apoios-colaboradores locais (técnica Bola de Neve) (KAUCHAKJE et al. 2006);

e) Representação da rede (offline e online) identificada em grafos e mapas (BRANDALIZE, 2009; DELAZARI, KAUCHAKJE, PENNA, 2005); e,

f) Análise a partir dos pontos de partida teóricos que permitem a atribuição de seu significado pelo pesquisador.

\subsection{Representação Espacial das Redes Sociais}

A primeira etapa da realização de um projeto cartográfico é o entendimento das necessidades do usuário, que permite identificar como os especialistas em redes sociais utilizam os grafos e as tabelas e quais são as análises a serem realizadas. Esta etapa foi realizada por meio de entrevistas com os usuários, da utilização dos grafos gerados offline com o software UCINET e dos grafos gerados online com o aplicativo TOUCHGRAPH, quando foram identificadas as seguintes análises espaciais a serem conduzidas sobre as redes:

a) Identificar as relações de proximidade e vizinhança. Com a utilização dos grafos, que apresentam a rede como um aglomerado sem relações de proximidade ou vizinhança entre os atores (conforme apresentado na Figura 1), não é possível visualizar as localizações espaciais dos atores e suas ligações;

b) Identificar a concentração de atores em determinadas regiões, o que poderá levar a importantes conclusões sobre porque algumas regiões são melhor assistidas socialmente do que outras. Além disso, é possível planejar a instalação de novos atores em locais sem assistência social;

c) Verificar as relações entre as características dos atores e a sua localização geográfica para permitir a análise de quais regiões são atendidas por organizações governamentais ou não-governamentais ou ambas;

d) Identificar a concentração geográfica dos atores da rede, considerando as diferentes esferas de governo: municipal, estadual, federal e global.

Tendo em vista que a literatura sobre cartografia não descreve outras pesquisas que tenham sido realizadas para propor uma solução cartográfica para o mapeamento de redes sociais, foram gerados mapas em papel, de acordo com as diretrizes de um projeto cartográfico convencional (MARCHIS, 2008). A escala do mapa foi definida considerando a distância mínima no mapa entre os dois atores mais próximos e a extensão do município de Curitiba. Como resultado obteve-se a escala 1:75.000 (figura 5), cuja base cartográfica é composta pelos limites de bairros. 


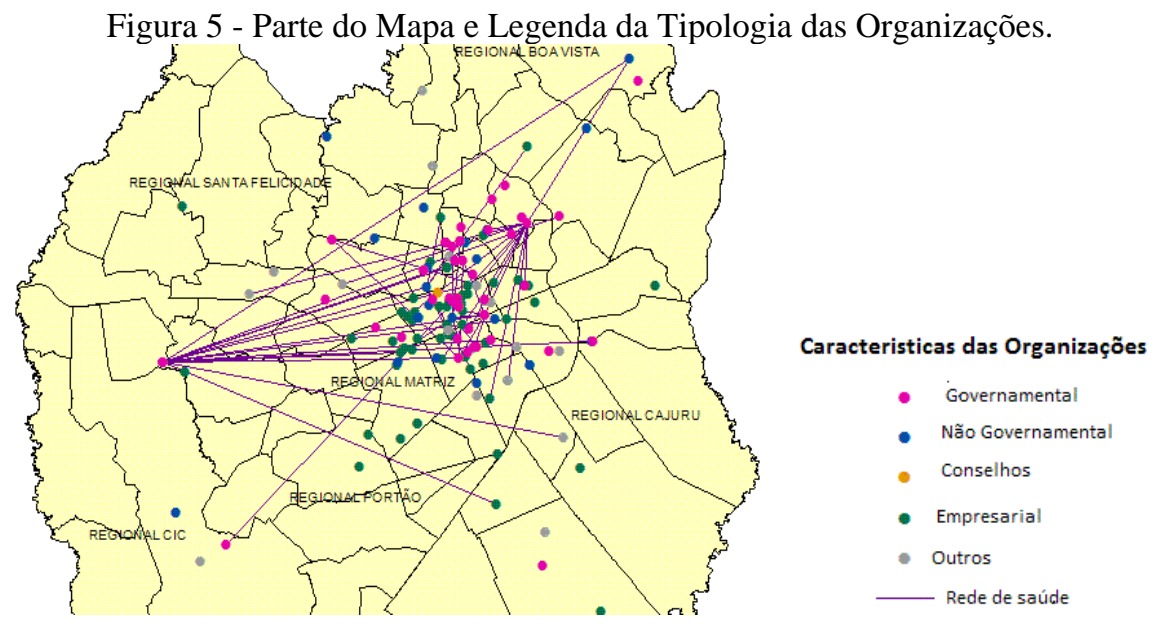

A representação online das ligações entre os atores e tipos de organizações, como apresentada nas figuras 6 e 7, utilizou os recursos de programação da localização (georreferenciamento dos nós da rede) do Google Maps. O Google Maps, ao contrário dos demais softwares utilizados, é uma ferramenta bastante divulgada e utilizada por usuários da Internet para a localização geográfica de diferentes fenômenos. Esta ferramenta é, de acordo com seus idealizadores, uma tecnologia de mapeamento bastante amigável que disponibiliza informações sobre comércio local, incluindo localização, contatos e rotas. Como o Google Maps utiliza a projeção cartográfica de Mercator e um sistema de coordenadas geográficas (latitude e longitude) vinculado, é possível localizar qualquer tipo de informação sobre o mapa através destas coordenadas. O software permite ainda a inserção de linhas e polígonos ligando pontos de interesse sobre o mapa. Assim, o mapa em questão foi gerado a partir da base de dados estática do UCINET que considerou a rede geral (portas de entrada, parceiros, apoio, colaboradores e links) e não a partir da base de dados dinâmica do TOUCHGRAPH. Neste contexto, a representação utilizou as cores e símbolos disponibilizados pelo Google Maps, tanto para a definição dos nós como para a definição dos enlaces. O georreferenciamento dos nós exigiu o levantamento e a programação de cada nó da referida rede (total de 39). Esta tarefa foi realizada utilizando-se a linguagem Google Maps API baseada em JavaScript. Ressalta-se que a Linguagem Maps API é uma linguagem disponível para qualquer sítio da Internet, livre de qualquer custo aos usuários. O JavaScript, por sua vez, é uma linguagem para desenvolvimento na Web que permite alterações dinâmicas, por parte do usuário, em páginas existentes. O mapa pode ser então disponibilizado, via Internet, para visualização pelos demais integrantes da equipe do projeto. 
Figura 6 - Representação Online da Rede de Direito Social Terra e Habitação em Curitiba - Escala Global.

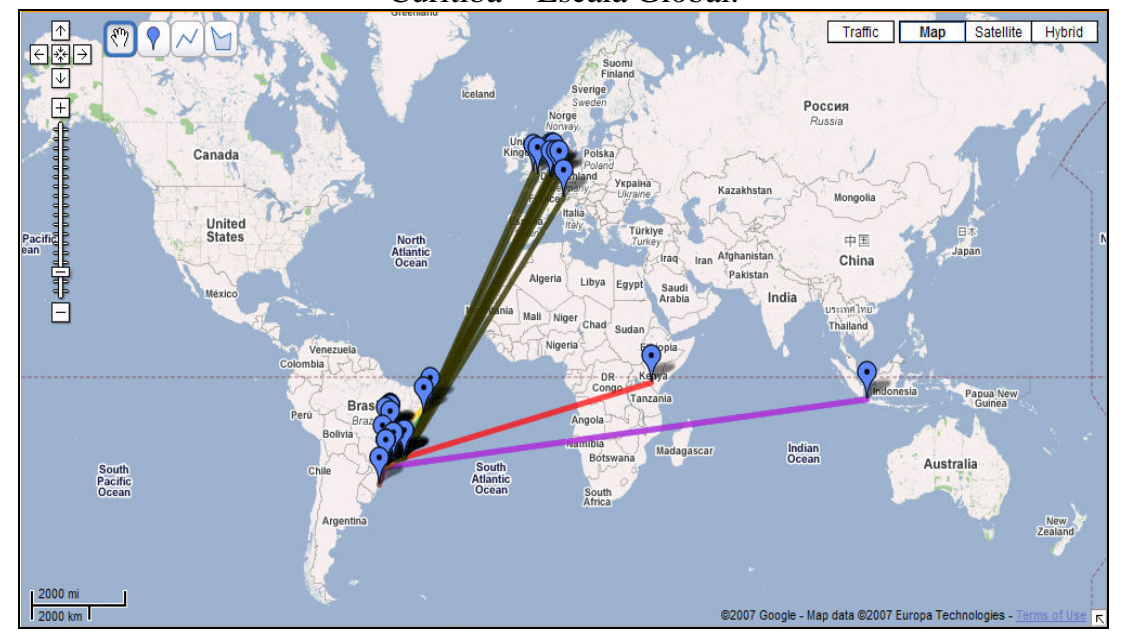

Figura 7 - Representação Online da Rede de Direito Social Terra e Habitação em Curitiba - Detalhe.

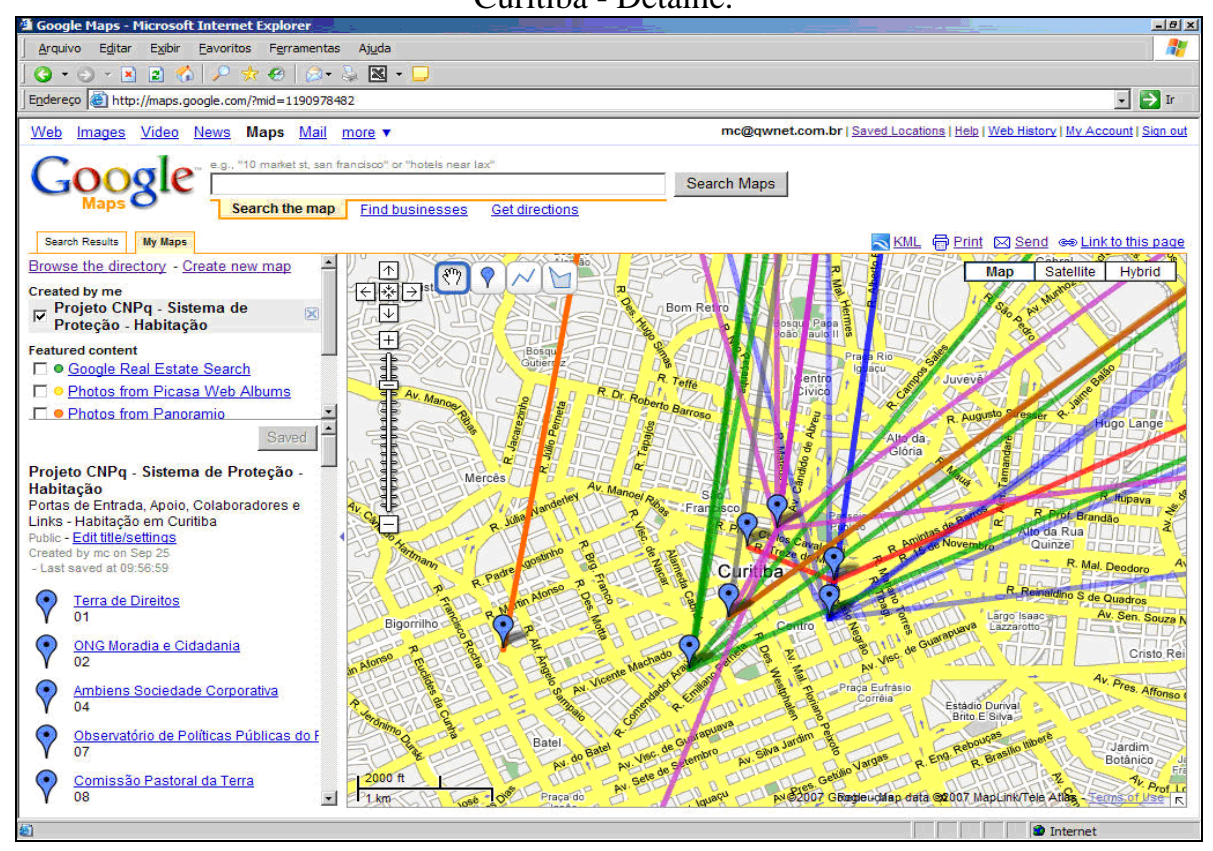

Bol. Ciênc. Geod., sec. Artigos, Curitiba, v. 18, nº 2, p.185-202, abr-jun, 2012. 


\subsection{Análise dos resultados}

As análises foram conduzidas considerando dois momentos distintos: aquelas realizadas quando do uso da informação pelos usuários, no sentido de responder aos questionamentos apontados no item 3.2; e as realizadas considerando os aspectos metodológicos para geração das representações.

\subsubsection{Análises realizadas pelos usuários}

Entre as redes sociais identificadas na pesquisa exemplificam-se as interpretações imediatas possibilitadas pela representação espacial da rede de segurança alimentar (Figura 5). Esta é uma rede em que são numerosas as organizações governamentais ou estreitamente ligadas ao Estado, seguidas dos Conselhos e Fóruns e, em número menor, estão as organizações empresariais e humanitárias. A Figura 5 permite observar que a maioria das organizações está localizada, basicamente, na regional Matriz, nos Bairros tradicionais e valorizados em termos imobiliários e com concentração de serviços e equipamentos públicos de qualidade.

A visualização da localização das organizações espaciais permite refletir sobre os dados referentes ao tipo de organização predominante em cada localidade bem como ao tipo de enlace. Isto permite buscar o conhecimento das características e especificidades espaciais (neste caso as divisões regionais) para estabelecer relações analíticas e explicativas sobre predominância, em certos lugares, de organizações de caráter movimentalista ou filantrópico ou acerto sobre parcerias temáticas ou para elaboração de projetos, por exemplo. Ao mesmo tempo, a representação da rede nos mapas temáticos possibilita a apreensão da possível influência da configuração cultural e sócio-econômica da localidade sobre as características das organizações ali presentes, e também, o impacto destas organizações sobre a configuração do espaço (KAUCHAKJE, 2008).

\subsubsection{Análises realizadas sob o ponto de vista da cartografia}

As análises decorrentes dos experimentos realizados concentram-se nos pontos a seguir:

a) $\mathrm{O}$ conhecimento das atividades desenvolvidas pelo usuário das representações cartográficas é a principal etapa a ser conduzida no projeto cartográfico, pois dela depende a eficiência das informações representadas.

b) Em um processo de visualização cartográfica, durante a análise das informações espaciais, a aquisição de conhecimento é possível se as soluções gráficas definidas para as representações proporcionarem a interpretação eficiente das características dos fenômenos analisados. Estas soluções devem representar tanto o comportamento espacial do fenômeno, como também enfatizar as características importantes para cada momento da análise. Isso foi obtido por meio de diversas entrevistas com os usuários, num processo interativo de construção do conhecimento. 
c) Verificou-se que as representações geradas na pesquisa e apresentadas sucintamente neste texto enquadram-se em praticamente todos os objetivos do processo de análise visual, a saber: exploração, análise, síntese e apresentação. Pode-se afirmar que os mapas atenderam aos objetivos de:

I. Exploração, pois o exame dos dados brutos permitiu uma análise global da configuração da rede;

II. Análise, pois a manipulação de dados conhecidos na procura por relações desconhecidas, e respostas a questões específicas permitiu aos usuários levantar hipóteses sobre as diferentes configurações apresentadas;

III. Síntese, pois possibilitou ao usuário a construção de novos conhecimentos;

IV. Apresentação, pois transferência de uma mensagem prédeterminada auxilia a fazer o encadeamento de novos conhecimentos na pessoa que acessa a representação. A visualização aplicada à apresentação permite o uso dos mapas por qualquer pessoa.

d) Os resultados obtidos até o momento permitem afirmar que as representações cartográficas podem ser combinadas com indicadores sociais para potencializar o poder das análises. A utilização das funções existentes nos Sistemas de Informações Geográficas permite que tais dados possam ser combinados e que os resultados sejam analisados em conjunto com as redes representadas espacialmente.

Vale ressaltar que diferentes aplicativos produzem diferentes resultados. Assim, os mapas gerados a partir dos dados obtidos nos sítios, executados inicialmente com o UCINET para cada rede de direitos, não produziram os mesmos resultados em termos de centralidade e enlace dos nós que a investigação conduzida online e automaticamente através do TOUCHGRAPH. Ocorre que, ambos constituem representações da mesma rede de direitos, porém, investigadas em momentos distintos. No caso do UCINET, a base de dados é estática e os resultados produzidos serão sempre os mesmos, mesmo que o aplicativo seja executado inúmeras vezes. Por outro lado, como o processamento do TOUCHGRAPH é online e a base de dados é construída automaticamente a partir de palavras chaves, e apresenta caráter dinâmico, gerando novos resultados toda vez que o aplicativo é executado e toda vez que o conteúdo dos sítios que compõem a rede é atualizado.

\section{CONCLUSÕES}

Pode-se afirmar que os resultados obtidos com esta pesquisa mostram que novas formas de representação da rede precisam ser propostas, bem como novas estratégias metodológicas para aprimorar suas construções. Os pontos mais importantes e que devem ser objeto de novos estudos são: 
a) Deve ser gerada uma metodologia automatizada para converter os dados coletados da rede, digitados em planilhas, para que o software utilizado para representar espacialmente a rede possa interpretá-los. Isso eliminará diversas tarefas manuais realizadas e que são fontes de erros.

b) Essa automação permite afirmar que, somente com o desenvolvimento de um sistema específico para realizar as representações, será possível gerálas em tempo menor e com possibilidades de análises potencializadas. Isso porque podem ser implementadas outras funções que o atual software para representação não permite realizar.

Afirma-se que é de fundamental importância que seja desenvolvido um sistema para múltiplas representações para análise de redes. Até o momento, conforme foi constatado ao longo da execução da pesquisa, por meio das descrições e estudo dos softwares para análise das redes, as soluções são complementares, porém estanques.

Os resultados alcançados com a pesquisa, quando vistos em conjunto com as pesquisas correlacionadas (KAUCHAKJE, 2008), anunciam um avanço, tanto no campo das análises sobre as redes, especificamente no campo das políticas públicas, quanto no campo das representações cartográficas, visto que é um desafio realizálas, em função da sua complexidade e da diversidade de atributos associados.

\section{AGRADECIMENTOS}

Ao CNPq pela Bolsa Produtividade em Pesquisa - proceso número 308892/2008-9.

\section{REFERÊNCIAS BIBLIOGRÁFICAS}

BENEDICKT, M. Cyberspace: first steps. Cambridge: MIT Press, 1991.

BRANDALIZE, M. C. B. Metodologia de Mapeamento da Rede de Direito Social Terra e Habitação no Município de Curitiba. VI Colóquio Brasileiro em Ciências Geodésicas, 2009. Curitiba - PR.

CASTELLS, M. A Sociedade em Rede. (A era da informação, sociedade e cultura, v.1). São Paulo: Paz e Terra, 1999.

CONTRACTOR, N. S.; WASSERMAN, S.; FAUST, K. Testing Multitheorerical, Multilevel Hypotheses about Organizational Networks: and Analytic Framework and Empirical Example. Academy of Management Review, v. 31, n. 3, 2006, pp. 6981-703.

DELAZARI, L. S.; KAUCHAKJE, S.; PENNA, M. C. Sistema de Informação Geográfica da Política de Assistência Social do Paraná. Anais XXII Congresso Brasileiro de Cartografia, 2005, Macaé - RJ.

DODGE, M. R. Are There Any Good Maps of Cyberspace. Cybergeography.org, Centre for Advanced Spatial Analysis, University College London, 2002.

DODGE, M. R. The Role of Maps in Virtual Research. Dynamic Maps Workshop, Humlab, 2003.

DODGE, M.; KITCHIN, R. Mapping Cyberspace. 2001. New York: Routledge.

DODGE, M.; KITCHIN, R. Atlas of Cyberspace. 2001. Great Britain: Pearson Education Limited. 
FREY, K. Crise do Estado e Estilos de Gestão Municipal. LUA NOVA, São Paulo, v. 37, pp. 107-138, 1996.

GIBSON, W. Neuromancer. New York: ACE Books, 1984.

KAUCHAKJE, S. et al. Redes Sócio-Técnicas y Participación Ciudadana: Propuestas Conceptuales y Analíticas para el Uso de las TICs. REDES. Revista Hispana para el Análisis de Redes Sociales, v. 11, pp. 1-26, 2006.

KAUCHAKJE, S. Rede Sócio-Técnica e Garantia de Direitos nas Cidades: proteção social com suporte tecnológico em Curitiba. Relatório de Pesquisa, CNPq, 2008.

LEFEBVRE, H. The Production of Space. Oxford: Blackwell. Disponível em $<$ http://books.google.com.br/>, 1991.

MACEACHREN, A. M. Some Truth with Maps: a primer on symbolization and design. 1. ed., AAG, 1994. 129 p.

MARCHIS, C. Proposição de Projeto Cartográfico para Representação de Redes Sociais: Curitiba. Dissertação de Mestrado apresentada ao Programa de PósGraduação em Ciências Geodésicas da Universidade Federal do Paraná. Curitiba. Paraná. Brasil. 2008.

MARQUES, E. C. Estado e Redes Sociais: Permeabilidade e Coesão nas Políticas Urbanas no Rio de Janeiro. Rio de Janeiro: Editora Revan, v. 1, 2000, 350p.

MARQUES, E. C. Redes Sociais, Instituições e Atores Políticos no Governo da Cidade de São Paulo. São Paulo: Editora Annablume, v. 1., 2003, 231p.

PONTIN, M. Reflexive Frames: Picturing Second Geography. Space and Culture, v. 11, n. 51, 2008.

PRADA, J. M. Digital Networks and Physical Space. $2^{\text {nd }}$ Inclusiva-Net Meeting, Humlab, 3-14 March, Madrid, 2008.

RITS. Rede de Informações para o Terceiro Setor. (2006). Disponível em $<$ www.rits.org.br/redes_teste/rd_oqredes.cfm>

STALDER, F. The Logic of Networks: social landscapes vis-à-vis the space of flows. Disponível em <http://www.ctheory.net/articles.aspx?id=263>. 1998

WASSERMAN, S. et al. Models and Methods in Social Network Análisis. New York: Cambridge University Press, 2005.

WASSERMAN, S. and FAUST, K. Social Network Analysis: methods and applications. Cambridge University Press: USA, 1999.

(Recebido em maio de 2011. Aceito em janeiro de 2012). 